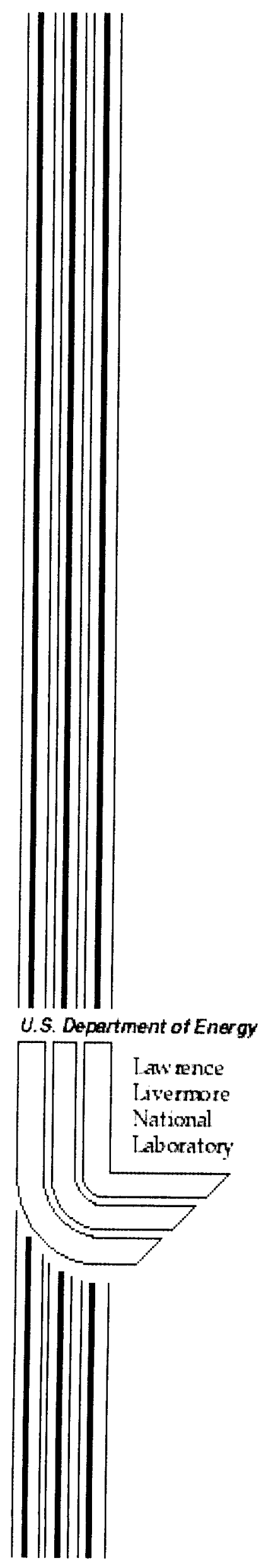

UCRL-ID-151695

\title{
MK-1 Removable Cryogenic Shroud (A Study of the Bimba Pneumatic Cylinder)
}

\author{
K. Anderson, D. Stefanescu
}

September 13, 2002 


\section{DISCLAIMER}

This document was prepared as an account of work sponsored by an agency of the United States Government. Neither the United States Government nor the University of California nor any of their employees, makes any warranty, express or implied, or assumes any legal liability or responsibility for the accuracy, completeness, or usefulness of any information, apparatus, product, or process disclosed, or represents that its use would not infringe privately owned rights. Reference herein to any specific commercial product, process, or service by trade name, trademark, manufacturer, or otherwise, does not necessarily constitute or imply its endorsement, recommendation, or favoring by the United States Government or the University of California. The views and opinions of authors expressed herein do not necessarily state or reflect those of the United States Government or the University of California, and shall not be used for advertising or product endorsement purposes.

This work was performed under the auspices of the U.S. Department of Energy by the University of California, Lawrence Livermore National Laboratory under Contract No. W-7405-Eng-48.

This report has been reproduced directly from the best available copy.

Available electronically at http://www.doc.gov/bridge

Available for a processing fee to U.S. Department of Energy

And its contractors in paper from

U.S. Department of Energy

Office of Scientific and Technical Information

P.O. Box 62

Oak Ridge, TN 37831-0062

Telephone: (865) 576-8401

Facsimile: (865) 576-5728

E-mail: reports@adonis.osti.gov

Available for the sale to the public from

U.S. Department of Commerce

National Technical Information Service

5285 Port Royal Road

Springfield, VA 22161

Telephone: (800) 553-6847

Facsimile: (703) 605-6900

E-mail: orders@ntis.fedworld.gov

Online ordering: http://www.ntis.gov/ordering.htm

OR

Lawrence Livermore National Laboratory

Technical Information Department's Digital Library

http://www.llnl.gov/tid/Library.html 


\section{MK-1 Removable Cryogenic Shroud}

A Study of the Bimba Pneumatic Cylinder

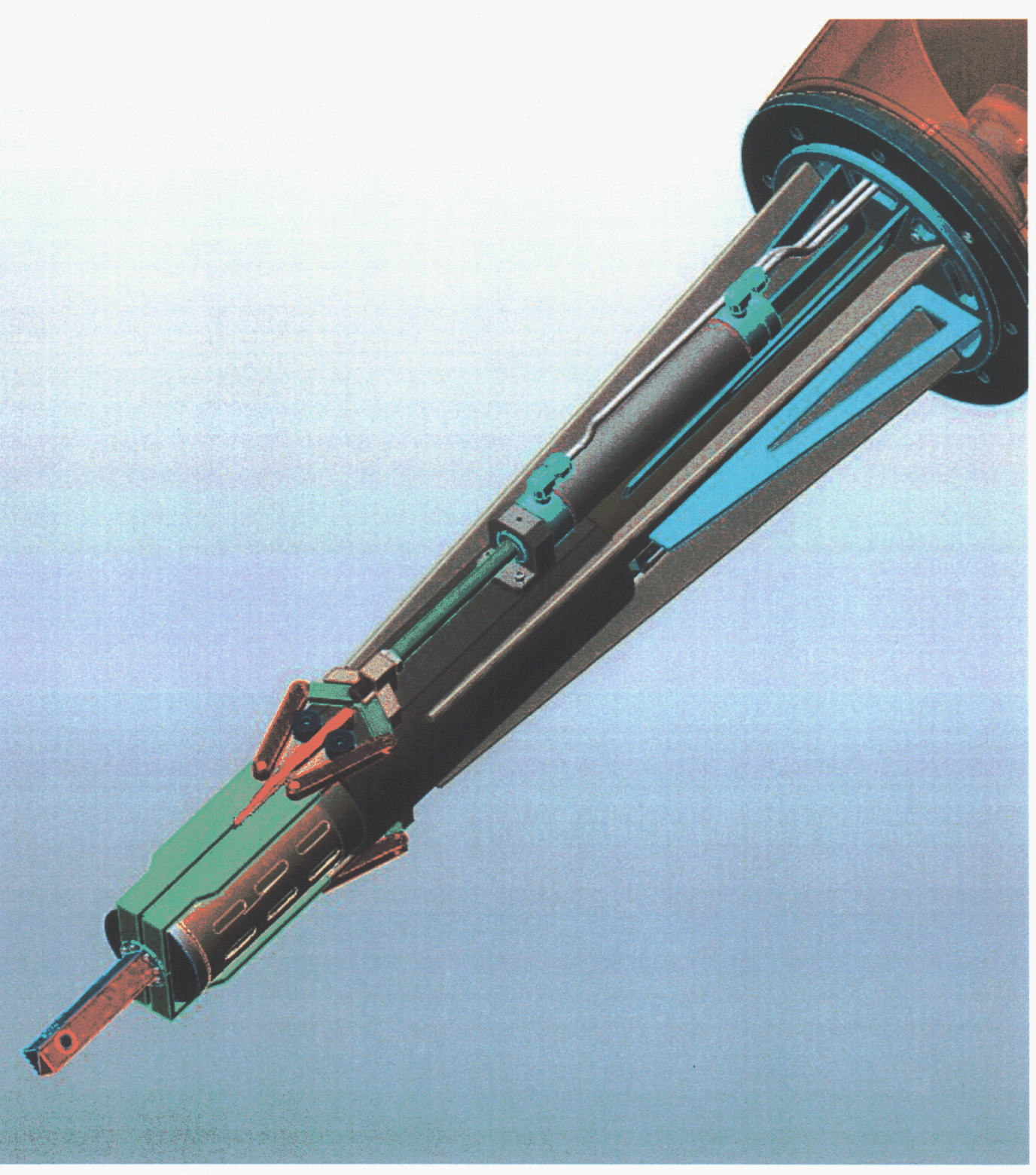

Kent Anderson, Stanford University

Daniel Stefanescu, LLNL

September 13, 2002 


\section{Contents}

\section{Abstract}

The Mark 1 Cryostat requires a cryogenic shroud that must be retracted immediately before firing the NIF laser. This paper evaluates a pneumatic cylinder that has been chosen to open and close the shroud. After a variety of motion control and vacuum compatibility experiments, we concluded that the Bimba feedback control cylinder may be used to retract the shroud with certain modifications to its control system and additional rod seals.

II. Overview of project $-1-$

III. Motion Control Studies
A. Bimba PCS Actuator
$-2-$
B. Test Results
$-5-$
C. Cylinder Designs and Tests without Bimba Controller
$-8-$ Board and Valve Manifold
D. Experimental Load Testing
$-10-$
E. Conclusions

IV. Vacuum Studies
A. NIF Constraint
$-13-$
B. Vacuum Experiments Results
$-13-$
C. Cylinder Leak Rate Experiments: Issues
$-13-$
D. Vacuum Experiments Conclusions
$-14-$
E. Vacuum Experiments Reference
$-15-$
$-18-$

$V$. Recommendations

V. Appendix

\section{Overview}

The Mark I Cryostat is a system that allows fielding of a wide range of targets on the National Ignition Facility (NIF). The purpose is to have a system with the capability of controlling the target temperature between $\sim 10^{\circ}$ and $300^{\circ} \mathrm{K}$.

While in the Target Chamber, a shroud must cover the cooled targets. This shroud allows the cold target to be shielded from condensable residual gasses in the target chamber. The removable shroud may be cooled to $80^{\circ} \mathrm{K}$ to provide a radiant shield for the target from the room temperature target chamber.

The shroud must remain over the target until approximately one second before shot time, and then retract on command, without inducing vibration into the target. An actuation system design, which removes the shroud, is constrained by the size limitations 
of the MK-1, the need to build from low-activation materials, the need to operate in a vacuum, and the need for high reliability. ${ }^{1}$

The scheme for retracting the shroud that we investigated was a pressurized air cylinder. The pneumatic cylinder tested in our experiments was built by the Bimba Manufacturing Company. We thought it would be suitable for shroud retraction because its manufacturer claimed that its motion was smooth, highly accurate, controllable and the appropriate size for our needs. The pneumatic cylinder moves a piston by changing the gas pressure in the two sections of the cylinder on either side of the piston. The cylinder also uses the piston as a voltage potentiometer to determine the current position of the piston. This voltage is then output to a controller card, which processes the voltage and compares it to the desired position input by the user. If the piston is not at the input location, the controller card dynamically controls the piston by opening and closing valves to the cylinder, varying pressure on the piston. The piston is connected to a shaft, which through a linkage system, attaches to the removable shroud. This report summarizes our studies of the controllability and vacuum characteristics of the Bimba Pneumatic Cylinder.

\section{Motion Control Studies}

The cryogenic shroud on the MK-1 must be fully retracted in 0.5 seconds to give adequate protection of the chilled target from condensation of residual chamber gas. This means that an actuator linked to the shroud assembly must make a 5.5 inch stroke in that time. This stroke must induce a smooth (i.e. sinusoidal) angular velocity on the shroud. The actuator must be very controllable to achieve this. With these restrictions in mind, I began evaluating the Bimba controller system, its valve manifold and the cylinder itself to determine whether it could be used for shroud retraction.

\section{Bimba Position Control System (PCS) Actuator}

\section{Control Overview}

The position of the shaft on the Bimba cylinder is controlled in the following way: The user sends the actuator an analog signal ( $0-10$ Volts), which corresponds to the desired final position. The voltage range and its corresponding physical positions are set by the user. The actuator then moves its piston to that location by opening and closing exhaust ports on the valve manifold, which varies pressure to either side of the piston. The motion is characterized by a sharp acceleration region, a constant velocity stroke, and a controllable deceleration region. The measured minimum time needed to complete one full stroke ( $\sim 6$ inches) is 0.7 seconds. The maximum velocity that the system can produce is $8.5 \mathrm{in} / \mathrm{sec}$, and the average velocity (which includes acceleration and deceleration) is approximately $5.5 \mathrm{in} / \mathrm{sec}$, unloaded. The accuracy of the final position and its stability are controllable. Two cylinders may be controlled using a single controller board and valve manifold, but it is not recommended by Bimba because feedback from one of the cylinders cannot be used to control its own position, which will reduce its accuracy and its synchronization with the other cylinder

\footnotetext{
${ }^{1}$ Summary of Project courtesy of Vaughn Brugman
} 


\section{Controllable Features: Settings for the PCS Board}

There are four toggles on the controller board that can be used to control the motion of the cylinder. The Dead Band is a toggle on the board that controls the accuracy of the actuator s final position. Using a digital voltmeter, you may set the Dead Band as low as $50 \mathrm{mV}$, which corresponds to being within $+/-0.03$ inches of the required position. When the actuator is within the Dead Band, it considers itself at the final position and closes all valves. When a force or leak in the system moves the actuator outside the Dead Band, the controller board automatically changes pressure in the cylinder to compensate and readjust the position.

The Decel Range is a toggle on the board that controls the deceleration region of the actuator stroke. Using a digital Voltmeter, this range may be set to any voltage between 0.5 and 13 Volts, which correspond to position voltages. The Deceleration sequence is characterized by about 7 steps of pressure equalization between the beginning (a decel range away from the final position) and the final position signal. If the range is too large, the actuator will take too long to complete the stroke. If it is too small, the actuator will overshoot its position target, and when accompanied by a small Dead Band, oscillate about the target position.

The Zero toggle adjusts the position of the cylinder that corresponds to a $0 \mathrm{~V}$ command signal. If set beyond the fully retracted or extended position, LEDs on the controller board will flash. The zero should be set such that both LEDs are off.

The Span adjusts the position of the cylinder that corresponds to a 10 Volt signal. To adjust the span, the cylinder must first be given a $10 \mathrm{~V}$ signal. The distance between the zero position and the $10 \mathrm{~V}$ position is used to determine scaling for the position signal and feedback. For Bimba Electrical and Pneumatic Schematic, refer to Fig. 1. 
Figure 1

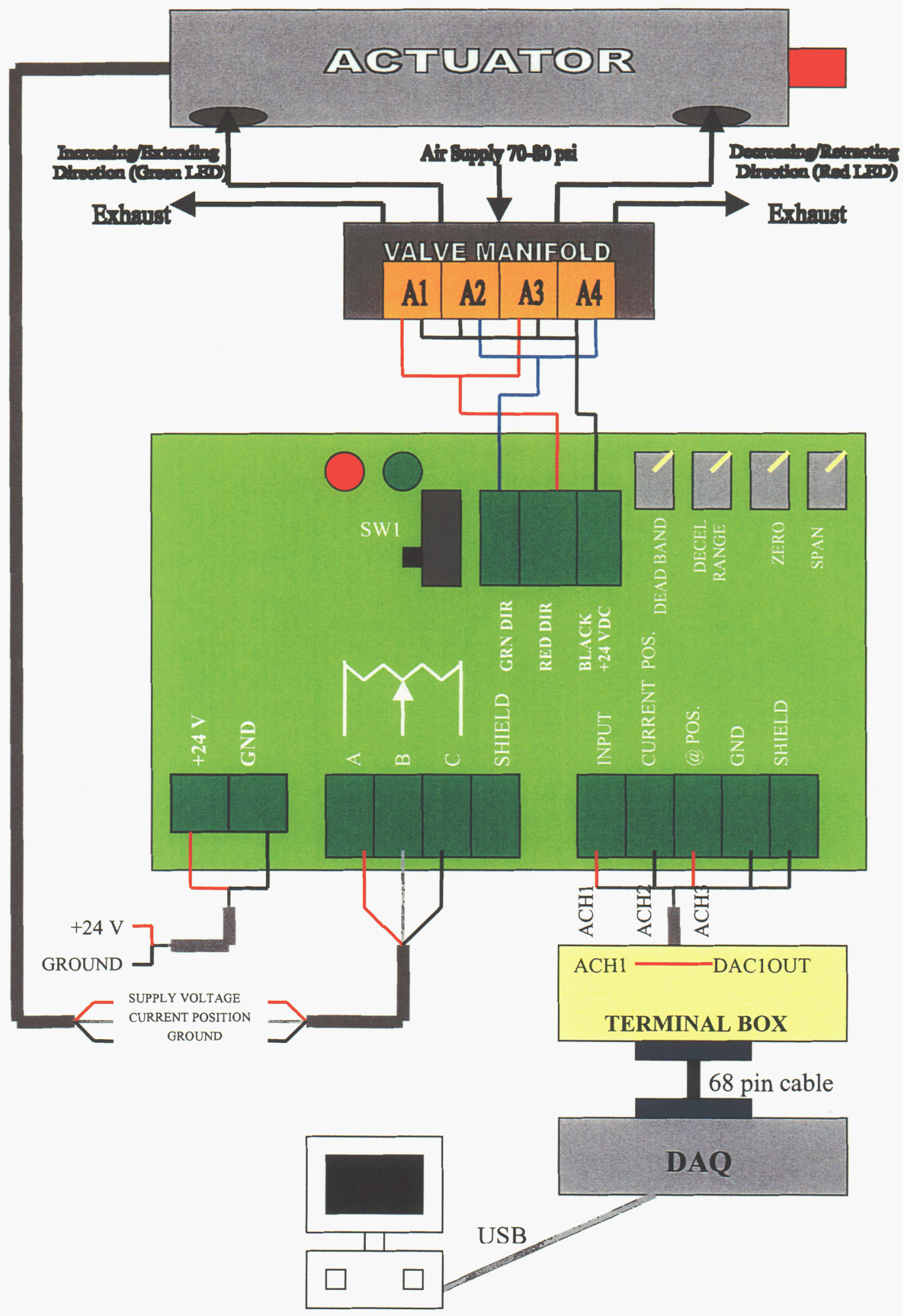

Bimba Cylinder Electrical and Pneumatic Schematic 


\section{Test Results}

The tests shown below evaluate speed, acceleration and response time in the Bimba controlled system.

Commanding full stroke (Fig. 2): At time $=0 \mathrm{sec}$, the cylinder was commanded to full retraction from full extension. The position vs. time output reading from the controller board was then recorded to determine the both the maximum velocity of the stroke and the time needed to fully retract the shaft.

Figure 2

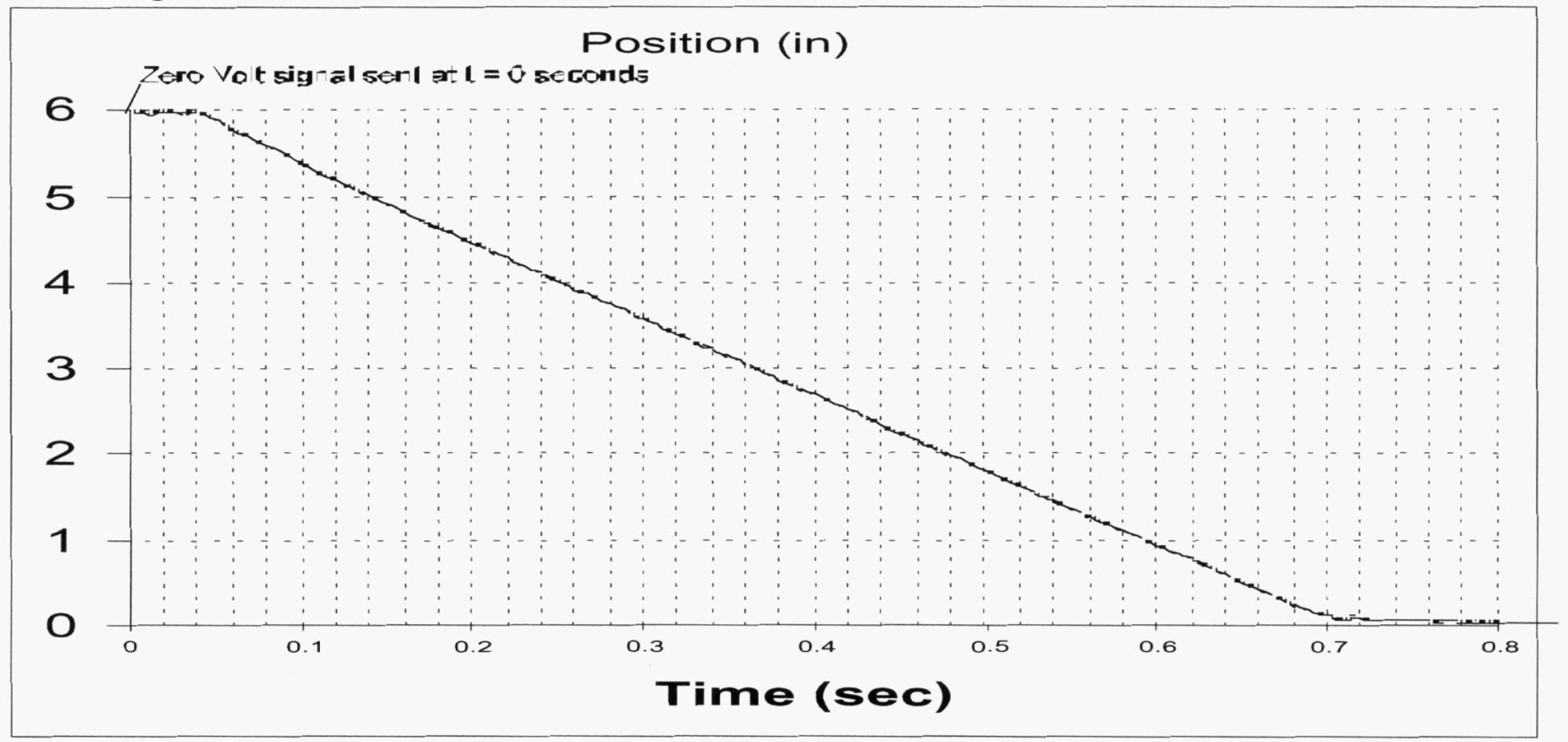

Acceleration for single point signal (Fig. 3): In this test, the actuator was commanded to full retraction. Using data taken every $1 \mathrm{~ms}$, the acceleration was then calculated using trapezoidal approximation and then a trendline in MS Excel. The max was $3000 \mathrm{in} / \mathrm{sec}^{\wedge} 2$.

Figure 3

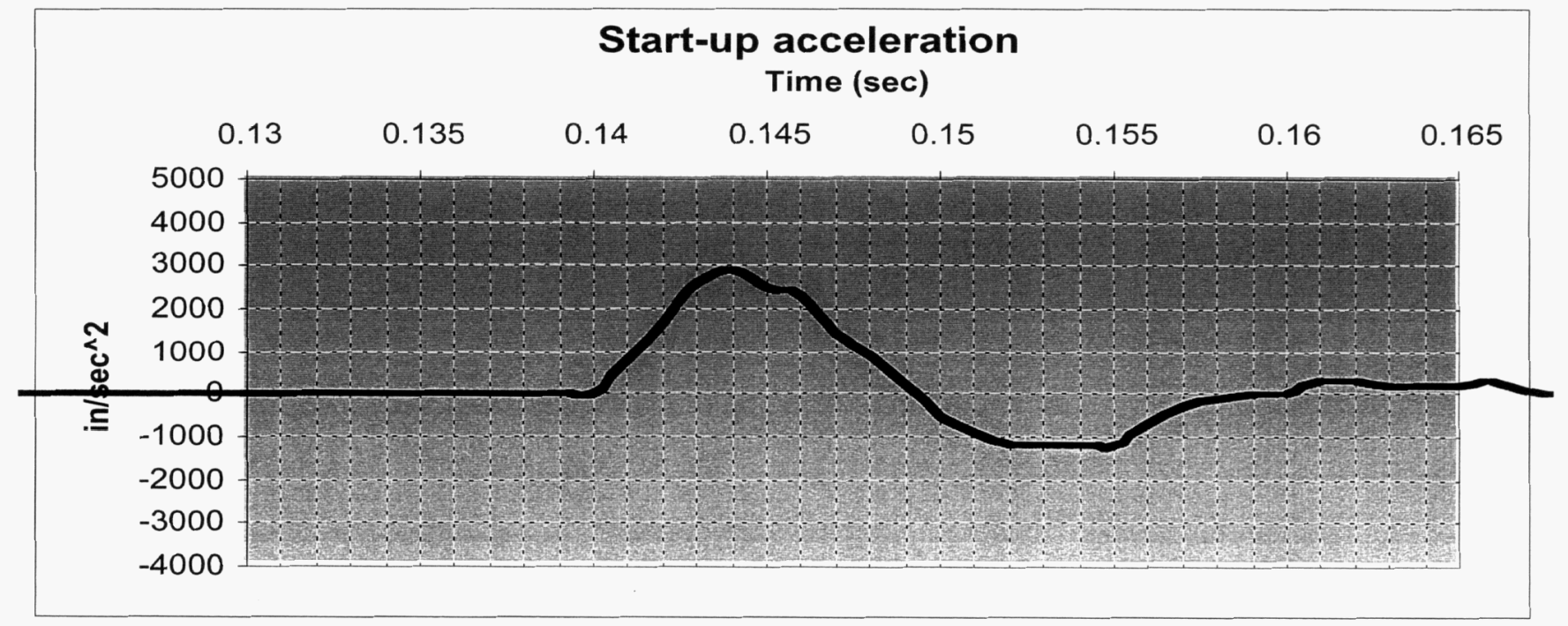


Response Lag (Fig. 4): Using a square wave signal, the response time of the Bimba controller and valve manifold was calculated to be $56 \mathrm{~ms}$.

Figure 4

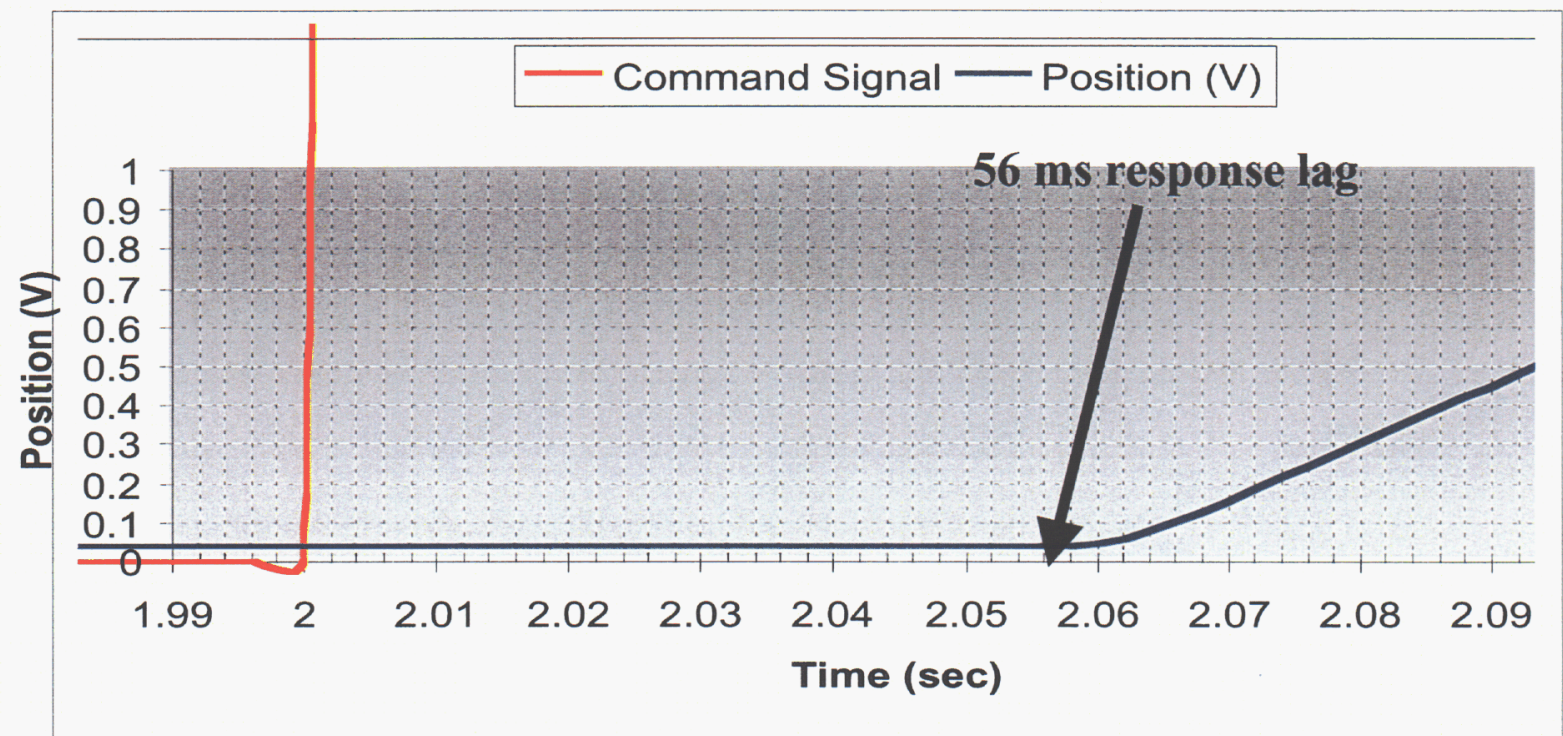

Signal Conditioning, not set point control (Fig. 5): The Cylinder was given a sinusoidal position signal with speeds never approaching the maximum speed of the system, to insure that the actuator would always be in the control region. The Dead Band was set to $20 \mathrm{mV}$, and the Decel Range is $0.5 \mathrm{~V}$.

Figure 5

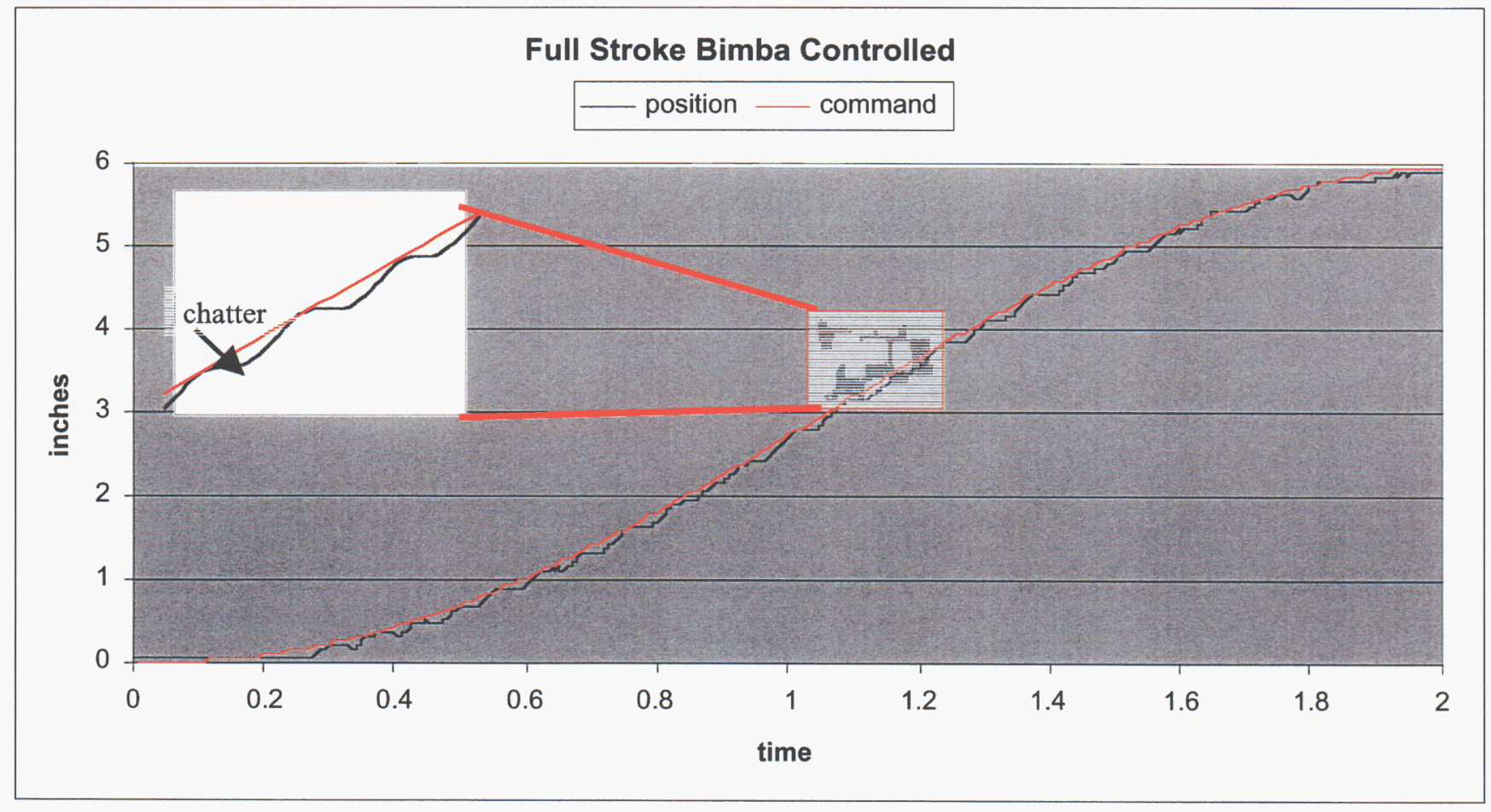


During signal conditioning we were able to see quite a bit of chatter (i.e. cyclical error in position) due to the nature of the on-off valve system. The frequency of the chatter could be directly related to the response time of the valves, which verified our hypothesis.

Decel Range Adjustments (figure 6): After finding chatter in signal conditioned motion, I decided to use Decel Range adjustments to smooth out the cyclical error, which I believed was due to repeated entrances into the Dead Band region. The first test I ran was on final position signals (unconditioned, set point command), which I needed to characterize the Decel Range toggle. As the Decel Range was increased, the piston approached its final position more gradually, but the time needed to stop the cylinder increased. Additional chatter was also introduced to the motion.

Figure 6

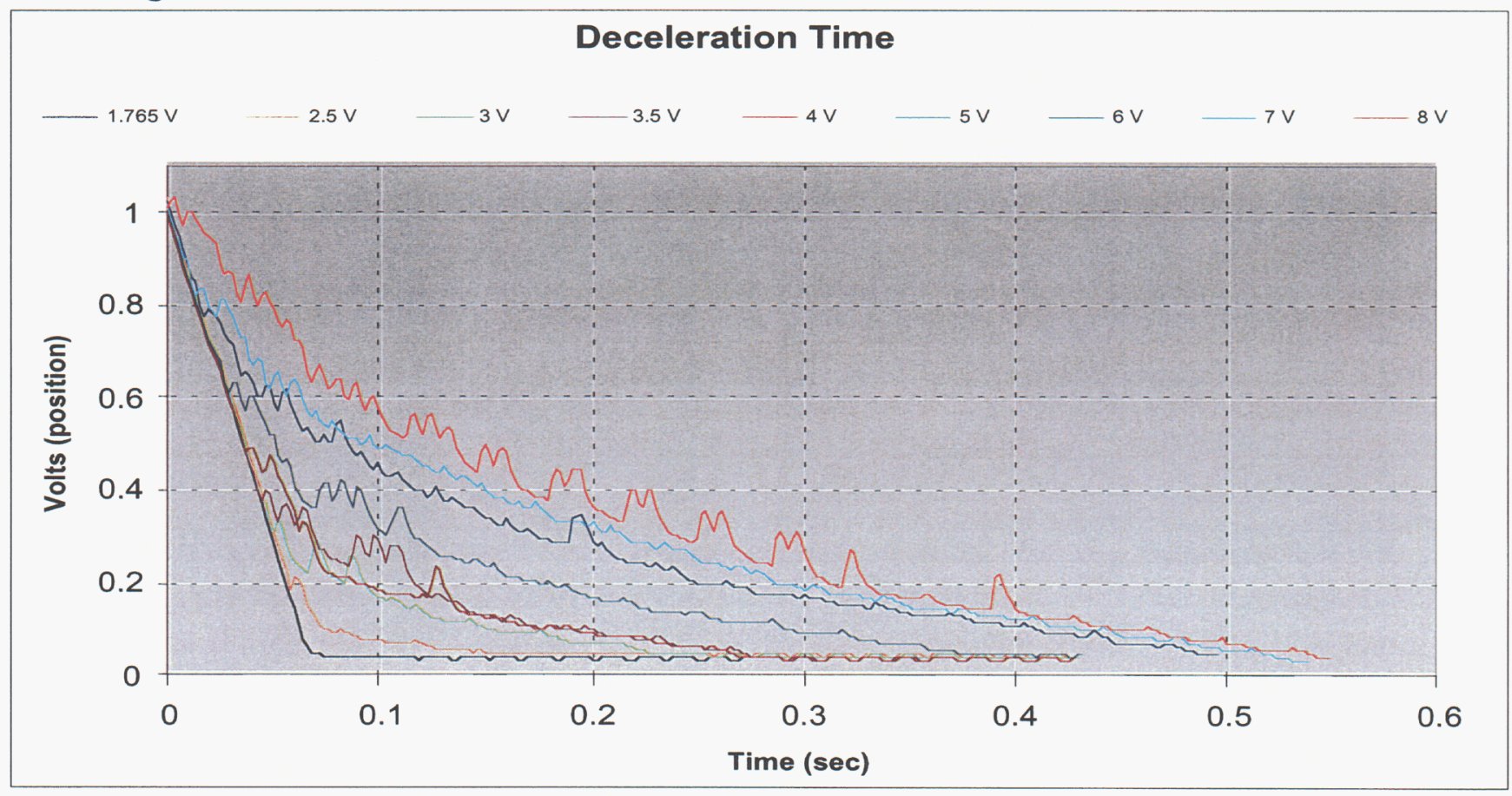

Signal Conditioning with Decel Range Adjustment (figure 7): To keep the cylinder from attempting to reach maximum speed, which created cyclical chatter during the stroke, I increased the Decel Range in the previous signal conditioning test to $4.5 \mathrm{~V}$. There was some reduction in the chatter and error, but it did not solve the problem.

Figure 7 


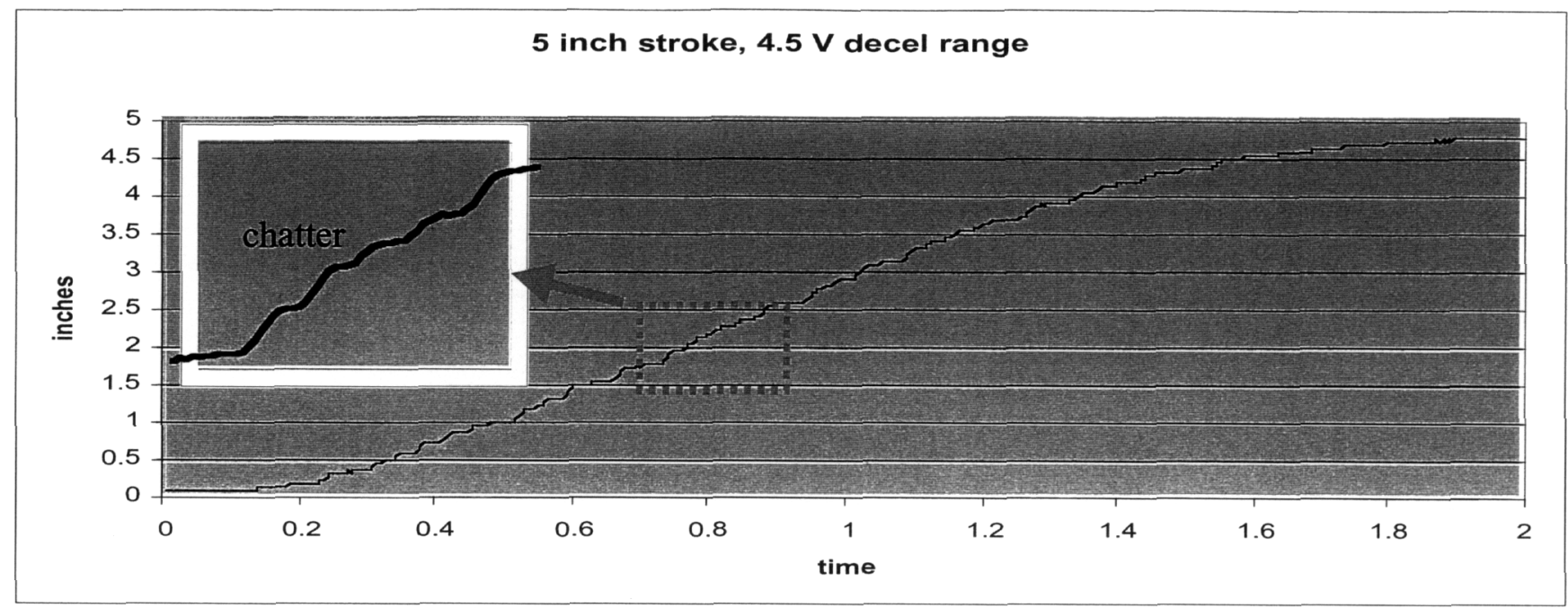

\section{Conclusions}

The valve manifold that came with the PCS controller uses $1 / 8$ ports. The orifices inside these valves are too small to handle the mass flow necessary for moving the cylinder in 0.5 seconds. As a result, this system, using these particular valves, does not meet specifications for the shroud assembly. The noticeable chatter while using signal conditioning also poses a vibration problem. Given the frequency of the chatter, it is most likely a result of the pulse modulated valves and controller board. However, since the system did not meet speed requirements, it was not necessary to fully quantify or resolve these vibrations.

\section{Follow-Up Testing}

After finding that the Bimba system could not meet speed and vibration requirements for the shroud retraction assembly, I then isolated the cylinder from the control system to test its performance. Through removing the controller board and valve manifold, I hoped to answer several important questions: 1) is the Bimba cylinder causing flow rate limitations on top of those from the valve system, 2) is it possible for a different system of valves to satisfy speed requirements for the Mark 1, and 3) can a system that moves fast enough be adequately slowed and controlled?

\section{Cylinder Designs and Tests without Bimba Controller Board and Valve Manifold}

In light of the problems encountered in the Bimba system, we chose to explore an open loop system for the Bimba cylinder. Our goal was to determine if we could eliminate the chatter by bypassing the control system. We also wanted to try simplifying the control system so as to possibly eliminate the need for a controller board altogether.

\section{Speed Test}

The most important test was to determine whether the speed limitation was a result of the $1 / 8$ valve manifold. Using $24 \mathrm{~V} 1 / 8$ solenoid valves with larger orifices to control airflow entering and exiting the cylinder, we constructed a limit switch circuit to 
stop the motion of the cylinder 1 inch from its fully retracted position. We tested this system at different pressures and found that the cylinder was capable of completing a stroke in 0.1 seconds using less than the 80 psi recommended for the Bimba control system. At pressures above 50 psi the limit switch was unable to adequately stop the actuator, so we began designing open loop control systems to slow and stop the actuator.

\section{Solenoid Valves and Balast Tanks}

Using a variety of tank sizes and pressures, the cylinder could be controlled simply through initial pressure settings, and operated by opening both solenoid valves. Refer to Fig. 8. The results of several test configurations with different initial conditions can be found in Fig. 9.

Figure 8

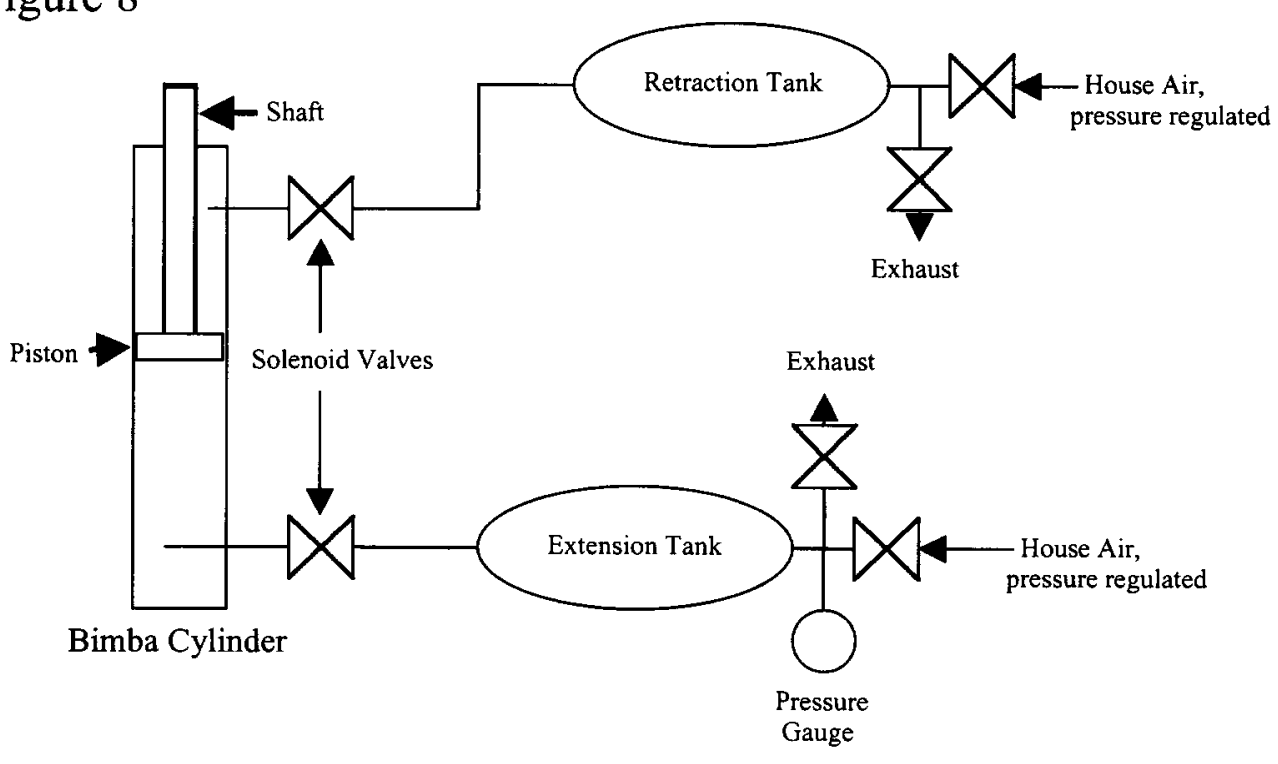

In some cases the extension tank was not used and the rear chamber of the cylinder vented to atmosphere. When operated in this manner we used springs to slow the motion.

\section{Actuator Position vs. Time Comparison for Different Initial Conditions}

Figure 9 
- No Retraction Tank, 40 psi house air, pressurized extension tank Exhaust to Air, 20 psi Retraction Tank, spring stopped

No Retraction Tank, 5 psi house air
Exhaust to Air, 40 psi Retraction Tank, spring stopped

Exhaust to Air, 10 psi Retraction Tank, spring stopped

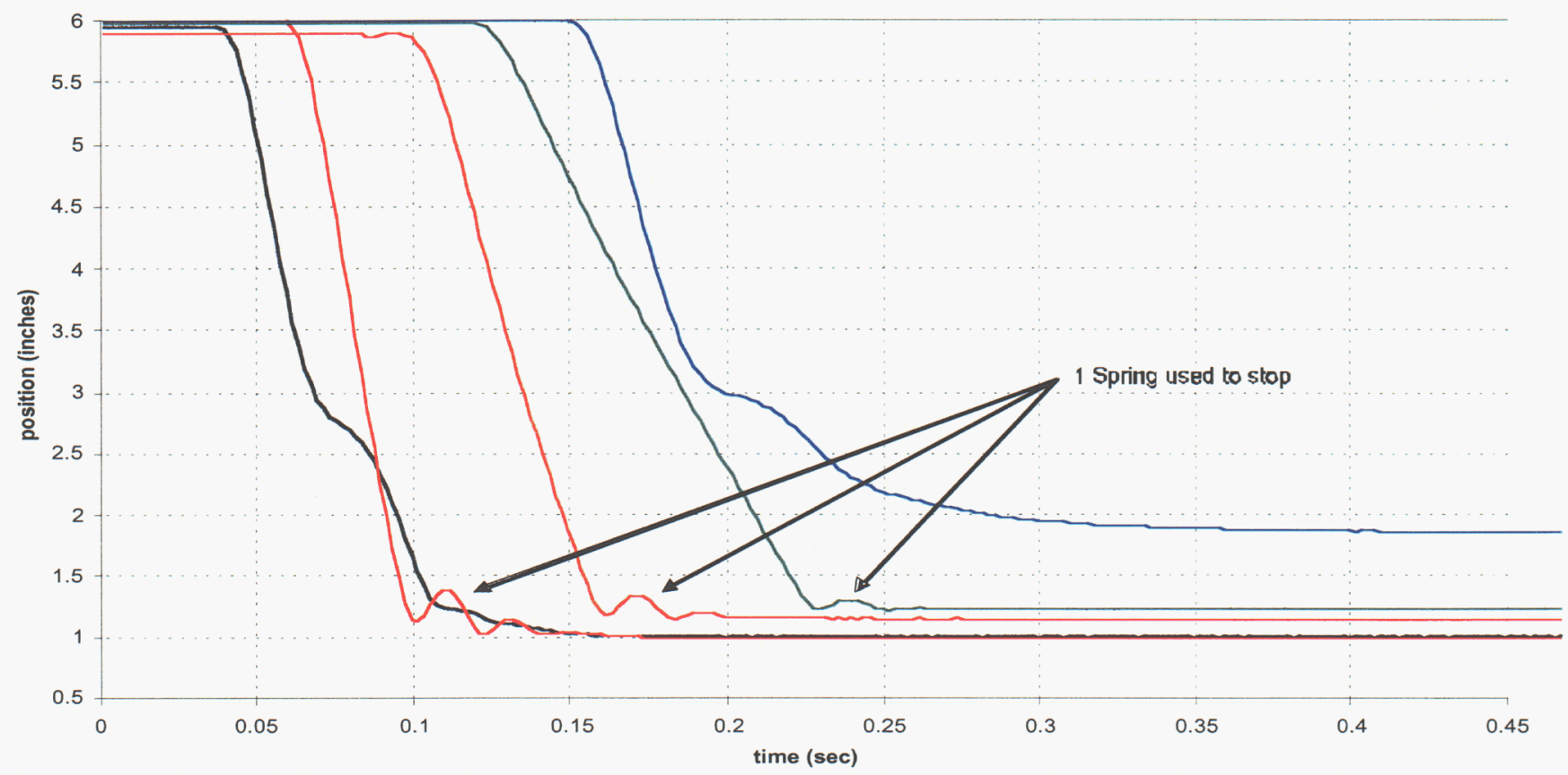

After running speed tests with the ballast tanks and finding that we were well within the time requirement for the cylinder actuation, we then moved on to controlling the deceleration of the piston using air. We assumed that the initial load would smooth out the acceleration portion of the stroke, so we focused on adjusting the initial conditions of the ballast tank system in order to build an open-loop control for the cylinder. By varying tank sizes and initial pressures, we determined that it was possible to move the piston in 0.5 seconds with a smooth deceleration (see Fig. 10).

Figure 10

Actuator Position vs. Time

Retraction Tank - 53 psig, no extension tank (space inside cylinder used to cushion stop)

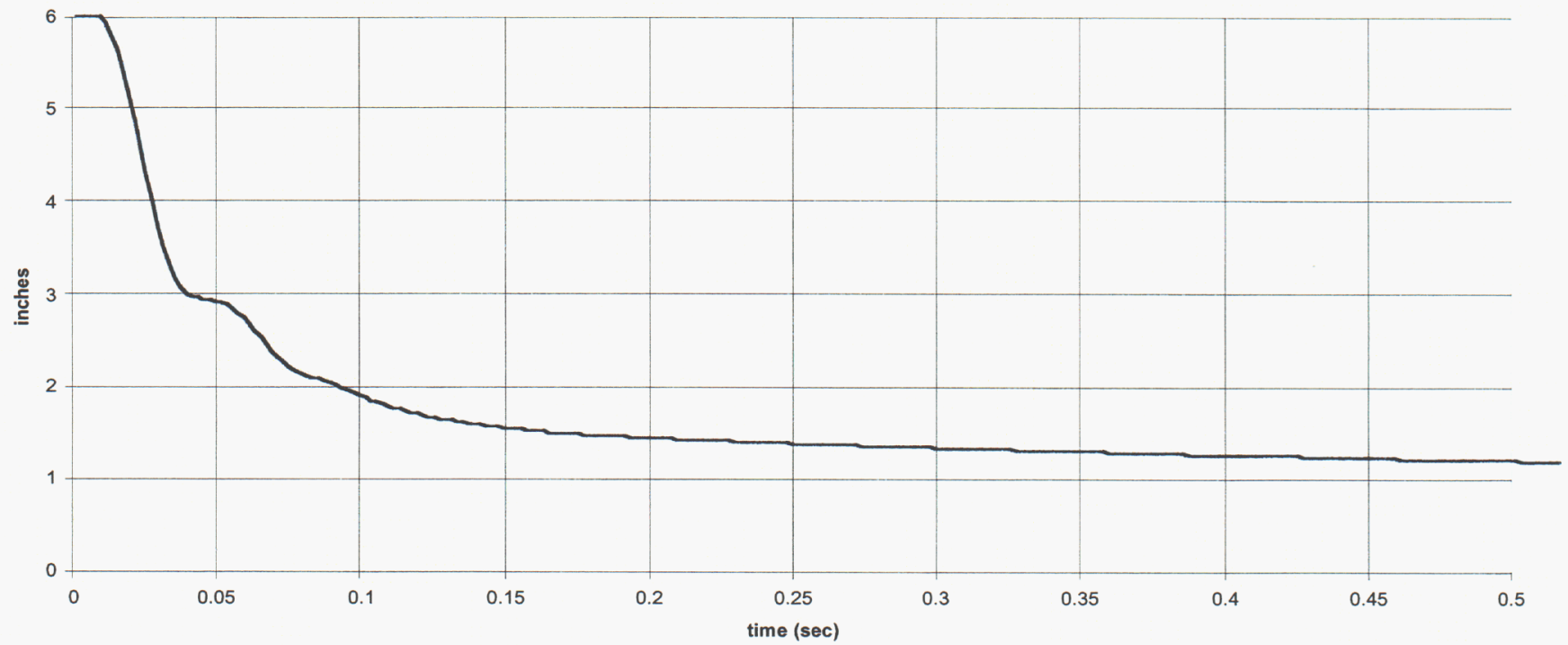


The noticeable mid-stroke bump is due to a spring effect of pressurizing and depressurizing the ballast tanks. The same effect has been seen in a basic simulation of this configuration.

Given these results we decided that no amount of adjustment to initial conditions could adequately control the cylinder s motion to fit the desired profile for smooth shroud retraction. We then began investigating use of a more continuous proportioning valve as a possible control solution. The Parker DYP010 valve and P/N 23-7030 controller are currently under evaluation and results have been promising.

\section{Experimental Load testing}

In addition to characterizing the free motion of the piston/shaft, we preformed several tests of the shaft motion while attached to an inertial load intended to simulate the load of the shroud. We hoped to simply determine whether mass-loading would slow the motion of the cylinder or smooth out the acceleration. After several runs we found that the load had no effect on the speed of the cylinder and no recognizable effect on the initial acceleration. This is due in large part to the negligible inertial force of the shroud that we were modeling, relative to the forces on the piston.

\section{Linkage Assembly Prototype}

After proving that the cylinder and available valves could pass speed and position requirements with an inertial load, we proceeded to prototype the linkage assembly. This was done to determine the position versus time profile for the actuator so that we could determine the desired shroud angular velocity curve. Additionally, it would help us better understand the linkages and best test the cylinder under the load of the shroud assembly. We constructed a shroud assembly using approximate dimensions for the links and aluminum material (see figure 11).

\section{Conclusions}

Building the linkage assembly prototype identified several important characteristics of the current linkage design. The current cam shape causes a small displacement in actuator position to correspond to a large angular sweep of the shroud in this region. This in turn causes the initial degrees of the shroud rotation to be very unstable. As a result, the actuator must be slowly eased into its motion to prevent suddenly jerking open the shroud. Additionally, there is a point of motion where the links separate from the cam induces over-rotation in the linkage. The actuator position at the separation point must be properly speed-controlled to prevent such slop in the motion. To accomplish this, the actuator must slow down in mid-stroke and this requires a more complicated actuator position profile. To resolve these issues, I designed an alternative cam that increases the initial displacement of the shaft necessary to open the shroud, and more gradually transitions through the point where the links break contact with the cam. This new design provides a smooth opening of the shroud with a simpler motion of the actuator. The alternative cam is pictured in Fig. 12.

Figure 11 - Linkage Assembly Prototype 


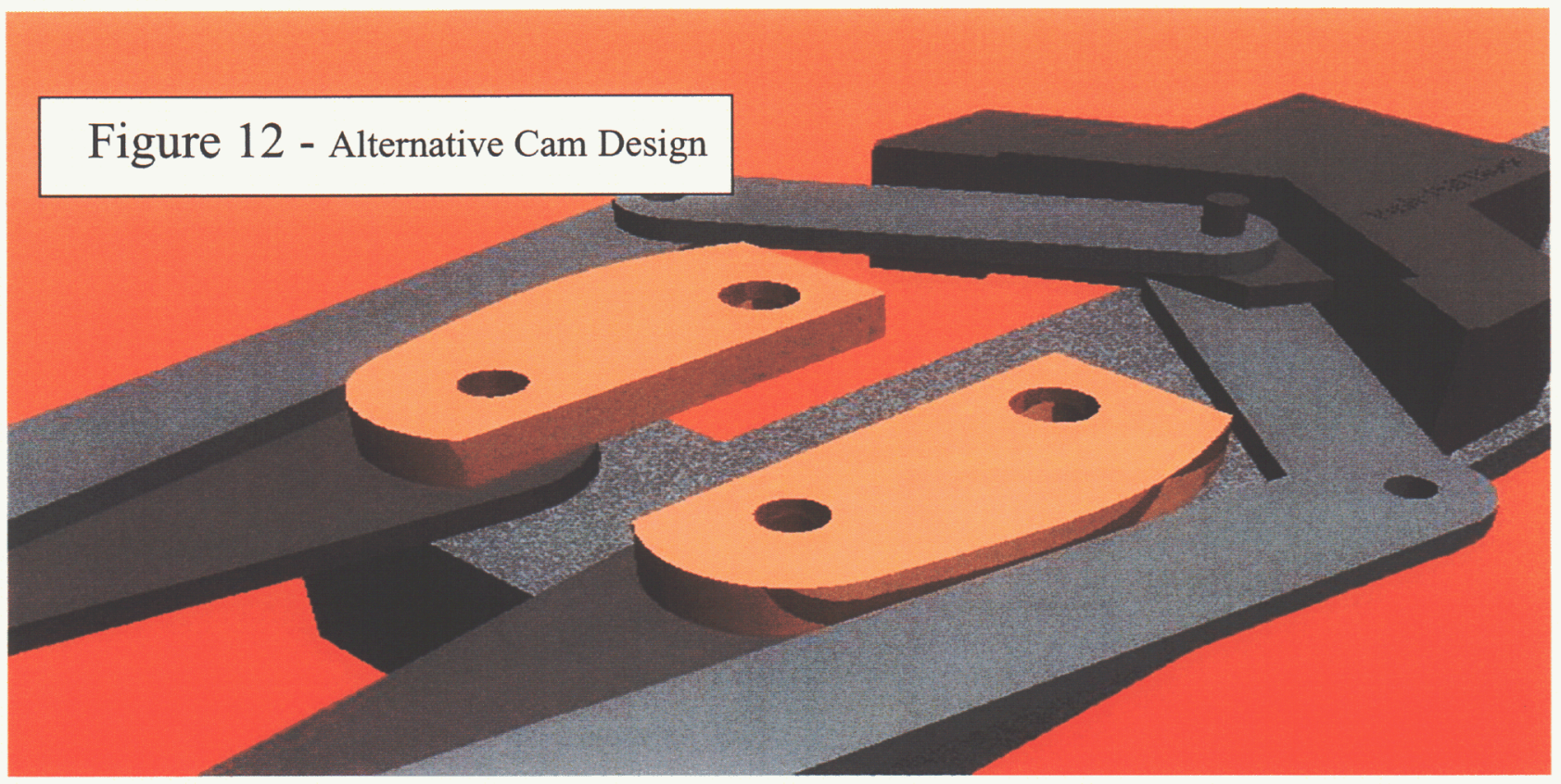




\section{Motion Control Studies Summary}

- The Bimba controller board and tested valve manifold do not meet motion requirements for the $\mathrm{MK}-1$ shroud retraction due to the vibrations they induce on the system and their inability to meet speed requirements

- The Bimba Cylinder under alternative control is suitable for shroud retraction

- Linkage assembly prototype may be used as a bench test for future valve and controller experiments

- The new cam design will simplify actuator requirements and optimize shroud retraction. I recommend further study on other alternatives in the assembly. 


\section{Vacuum Studies}

\section{NIF Vacuum Requirement}

According to specifications for the NIF chamber, the maximum allowable leak rate is 6.0E-5 $\mathrm{cc} / \mathrm{min}$ of gas at atmospheric pressure. The Bimba cylinders use pressurized air and have moving parts, so it is important to evaluate their potential contribution to the NIF chamber leak rate. We began a series of experiments to characterize and, if possible, improve the leak rate of the Bimba cylinder. The leak rate was measured using rate of rise tests. In the rate of rise tests, the cylinder was placed in a vacuum chamber with gas feed-through lines supplying it with pressurized air. The chamber was then evacuated and the cylinder was pressurized to either atmosphere or 80 psi. The measurements consisted of 1) sealing the feed through lines to measure the chamber background leak rate 2) pressurizing the cylinder to atmosphere 3) pressurizing the cylinder to $80 \mathrm{psi}$ and 4) actuating the cylinder. There were several iterations on the seals and chamber setup before we arrived at our minimum leak rate. Below is a summary of issues we discovered during these tests, which will be important for future vacuum experiments.

\section{Vacuum Experiments Results}

- Most, if not all, leakage from the cylinder escapes through the shaft seal (refer to experiment $8 / 20 / 02$ in appendix).

- Certain additional measures might need to be taken to bring the leak rate to spec

* The seal cartridge, which has an o-ring and a shaft seal, must be used (see figure 13).

* The interstitial space between the two seals in that component must be differentially pumped, unless different seals are used.

* The success of the differential pump is related to the pumping speed of the pump used and the area of the orifice through which it pumps - stronger pumps and larger orifices can improve the cylinder s overall leak rate. When using a roughing pump, backflow of oil can enter seal cartridge.

* The most successful design for the differential pumping so far uses an $1 / 8$ in. steel line that is welded onto a 6-32 vented screw, which is torr-sealed into a hole in the end piece (see figure 14).

* Alternate shaft seals, such as a differentially pumped double o-ring, must be investigated for the cylinder to meet specs while actuating.

* The leak rate of the Bimba cylinder with differentially turbo-pumped shaft seal inside of the seal cartridge is as follows:

- between 6E-05 and 9E-05 atm cc/min when not actuating

- between 4E-4 and 1E-3 atm cc/min while actuating

- higher after actuating (but still stationary) than before actuating

\section{Cylinder Leak Rate Experiments: Important Issues}

During the vacuum testing we encountered many issues that will be important for future leak rate measurements and cylinder vacuum experimentation. Each issue is accompanied by a reference to the experiment(s) that drew the conclusion. 
1. The Vacuum compatible grease used inside the cylinder outgases. While we were assured by Bimba that the cylinder would be made vacuum compatible, it is clear that certain products used inside the cylinder contribute to the leak rate in particular configurations. Therefore, when running tests on the cylinder, it is important not to measure leak rates with the inner chambers of the cylinder open to vacuum. It is also important to note that grease on the rod might also contribute to measured leak rates, though it is not my conclusion that this occurs during actuation of the piston, which was the greatest leak rate we found. This could partially explain why the cylinder leaks more after being actuated than before actuating, which is measured following several days of pump-down (and hence, out-gassing). See tests $8 / 26 / 02$ and $9 / 3 / 02$.

2. Only VCR connections should be used on lines to the interstitial space and to the chambers of the cylinder. After repeated high leak rate measurements and several counter-intuitive results in our first chamber experiment (see figures $15 \& 16$ ), we determined that compression fittings could not be used on air lines to the cylinder. In a related discovery, polyethylene tubing should not be used as well. The only way to bring the cylinder into NIF specifications is to eliminate all leaks other than the shaft leak entirely. We decided that we could only accomplish this with all steel lines and only VCR connections. See tests 8/23/02, 8/26/02 and 8/29/02.

3. The differential pump line can be a source of back streaming into the chamber. If the leak through the shaft seal is great enough, it is possible for the pressure in the interstitial space to be lower than in the pump used to evacuate that space. In our experiments we found roughing pump oil deposits inside of the seal cartridge, and subsequently changed our configuration so that the turbo pump used to pump down the chamber would also pump the interstitial space. See test 8/26/02.

4. Use calibrated gauges to measure pressure in the chamber. This might seem obvious, but because we were unable to access calibrated vacuum gauges for our tests due to limited resources and time, I find it necessary to include this issue. When using the rate of rise method to measure leak rates, small changes in the measured pressure and actual pressure might skew leak rate calculations by as much as 4 times. In future tests on the cylinder, only calibrated gauges should be used. See notes on vacuum tests below.

\section{Notes on Vacuum Experiments}

Rate of rise calculations were made based on data from uncalibrated gauges. Multiple types of gauges with different ranges were used to some degree to confirm measurements from each. While leak rates may not be exact, the purpose of these tests was to evaluate the Bimba cylinder concept: Can this cylinder come close to the NIF specification and if so, what adaptations to the design need to be implemented? Once a design for the cylinder and its seals has been finalized, additional tests with higher accuracy need to be conducted before the cylinder is to be placed in the NIF chamber. 


\section{Vacuum Experiments Conclusions}

Results suggest that we are slightly above the NIF leak rate limit using the cylinder with a differentially pumped interstitial space, without actuation. When actuating, the leak rate is more than a decade above the limit. We note that the cylinder leak rate is significantly (an order of 10) above the NIF spec only for a short time just before the laser shot. The overall effect of the gas puff into the chamber would need to be considered in light of the laser and diagnostic requirements. The Bimba cylinders may therefore require additional modifications to be NIF chamber compatible. Future experiments should explore different shaft seals, such as a double o-ring with differentially pumping, or use of a steel Bellows. I recommend that additional motion control studies be done with the bellows attached as it may change the force profile necessary for opening the shroud.

\section{Vacuum Experiments Reference}

Figure 13

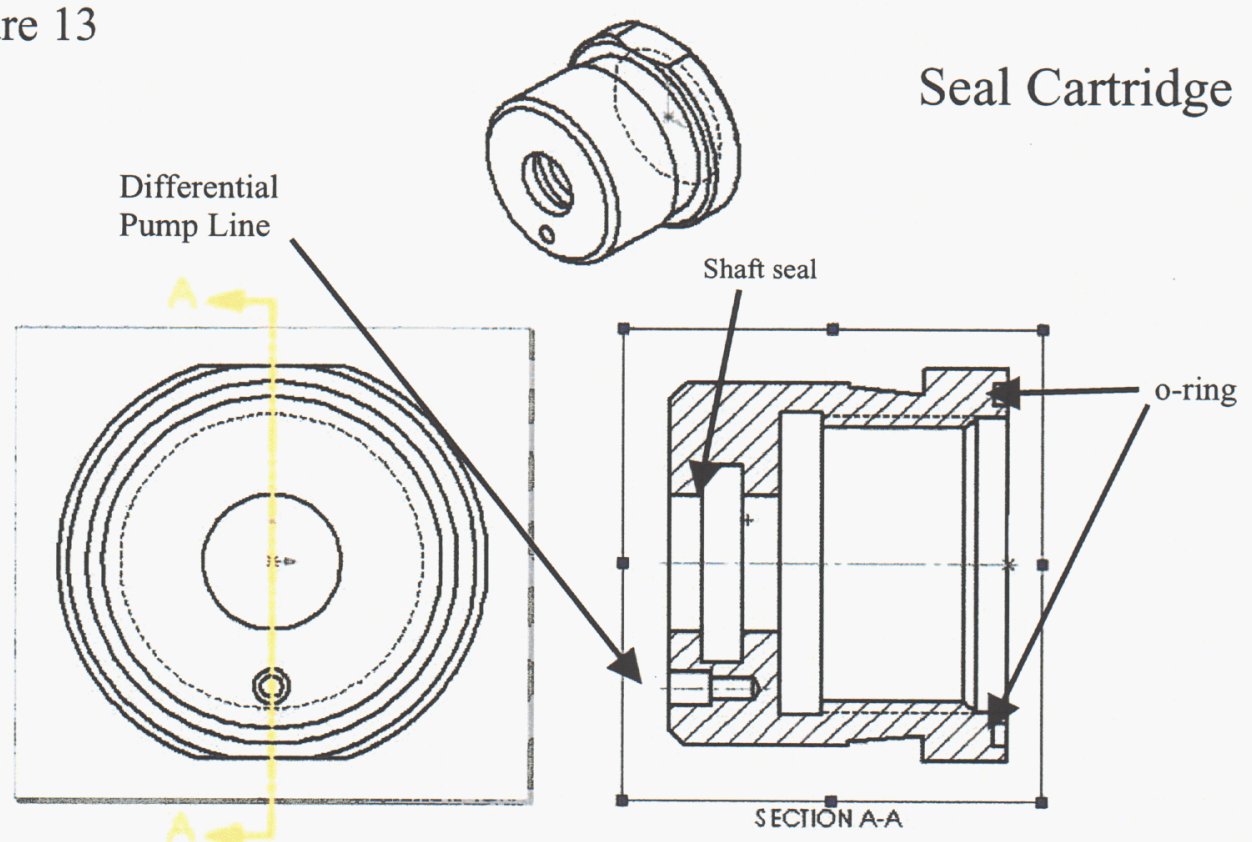

Figure 14
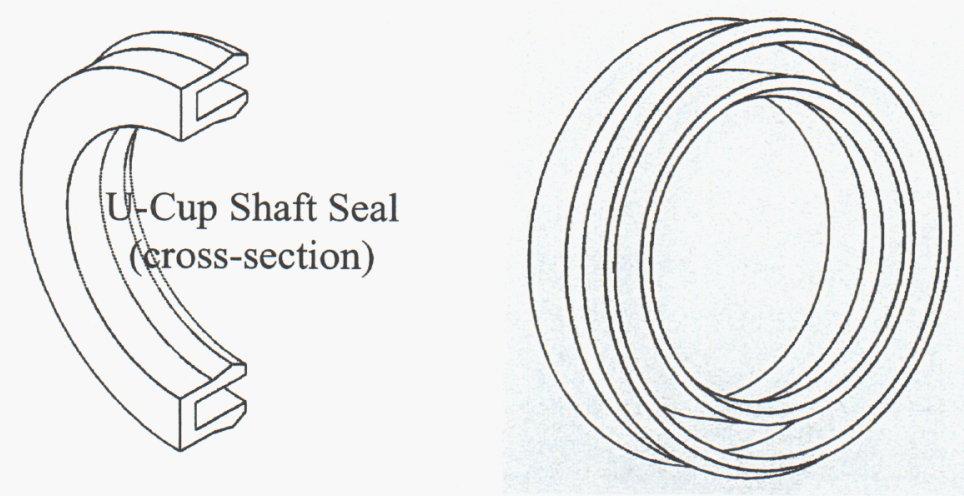

U-Cup Shaft Seal 
Figure 15
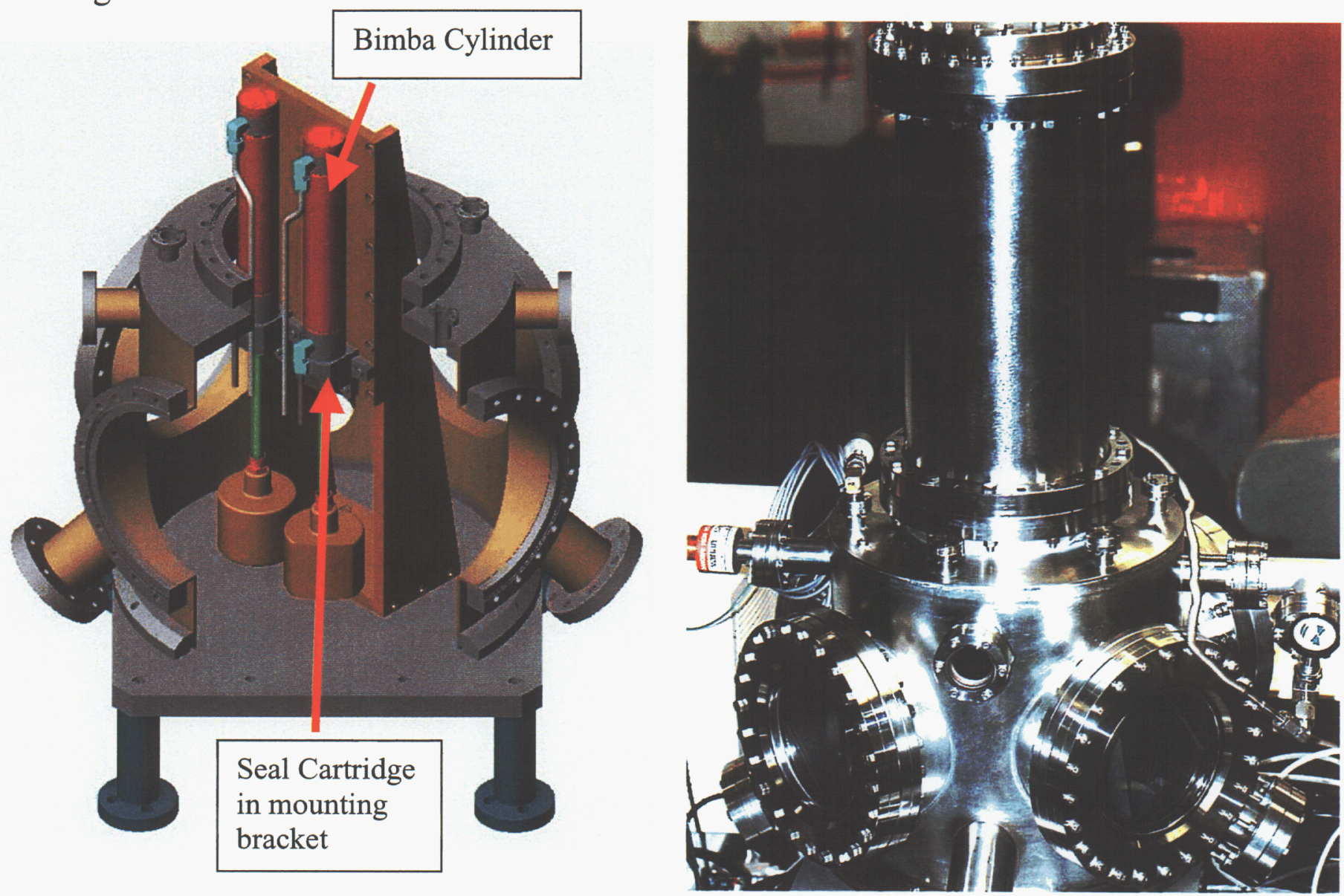

Figure 16

Chamber 1

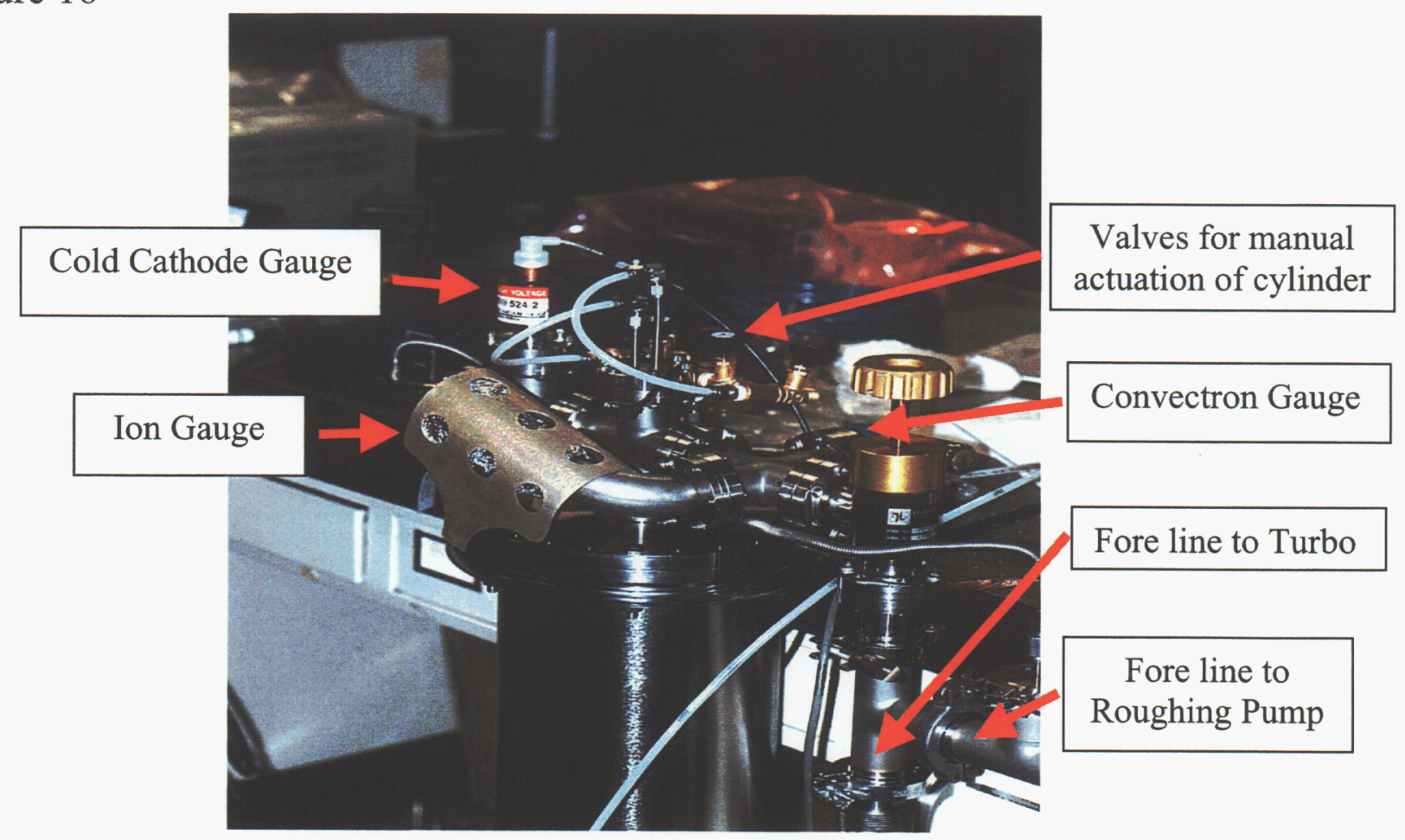

Chamber 2 


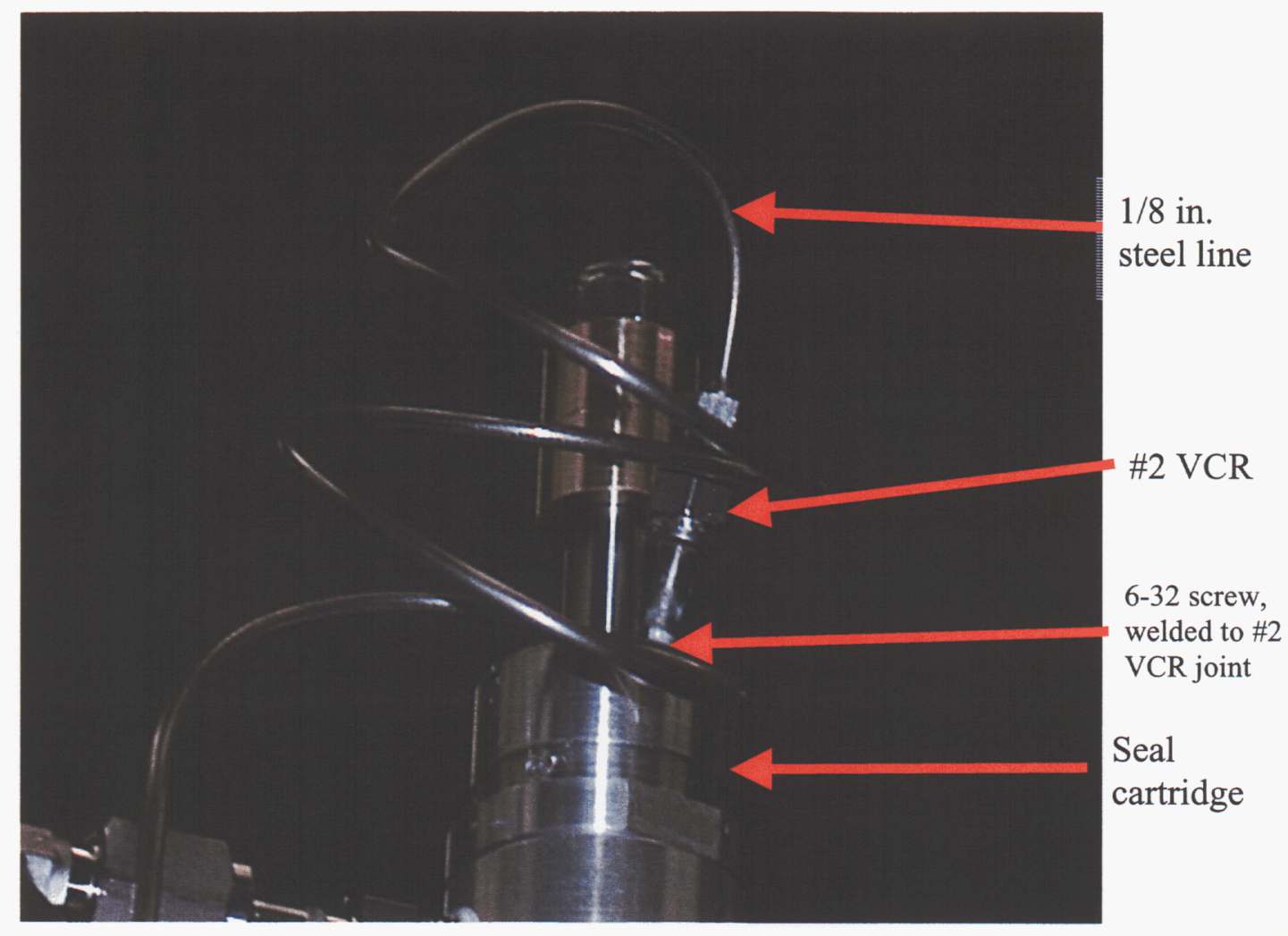

Differential Pumping Scheme

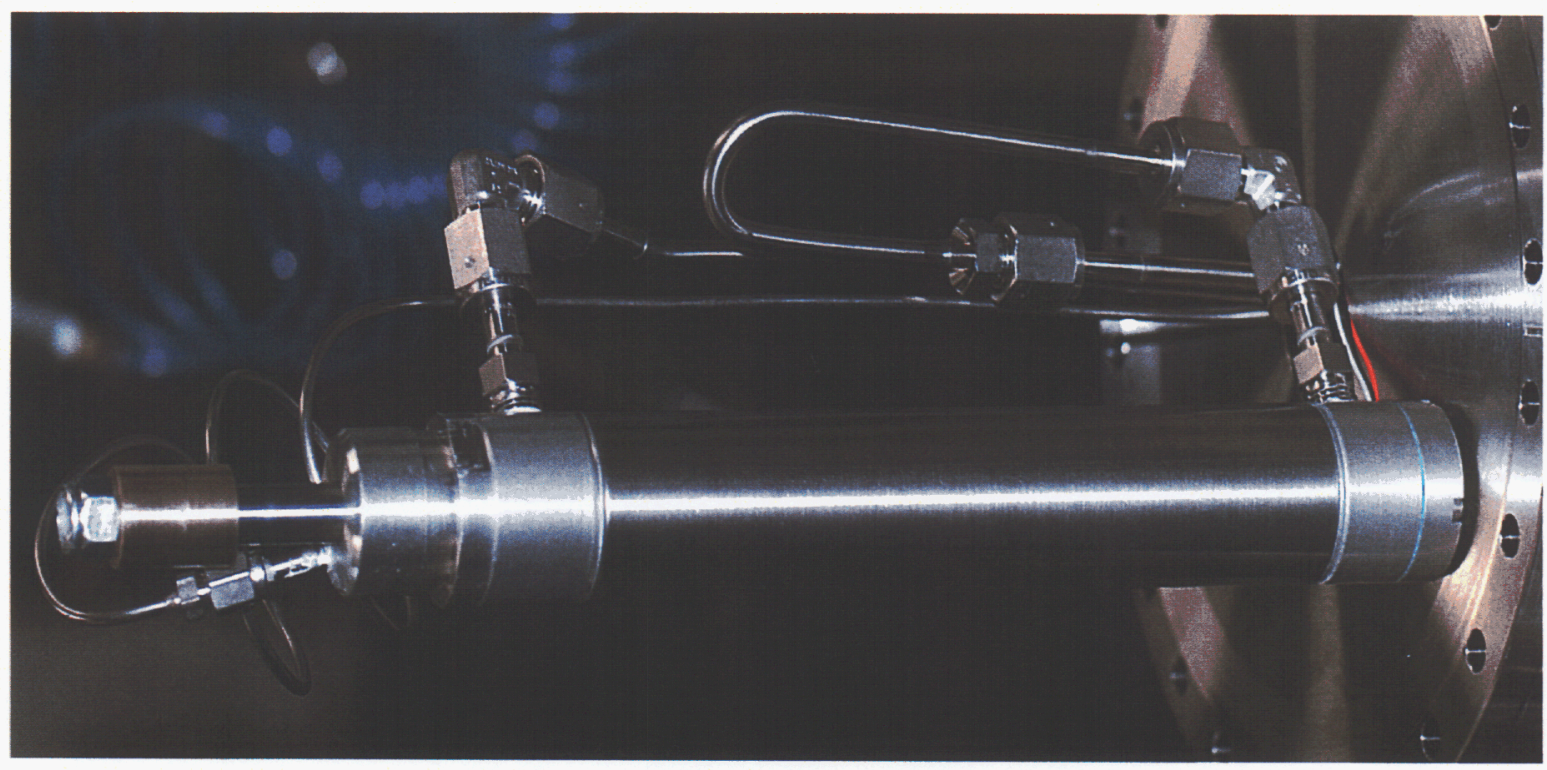

Cylinder Connections inside chamber 2 (all VCR) 
Recommendations

Based on the research I have done on the Bimba cylinder, I make the following recommendations for future work:

1. Leak rate reduction - The current method for controlling the cylinder s leak rate is inadequate. For the shroud removal system to fall reasonably within the NIF Chamber specification its stationary leak rate must decrease by about half and its leak rate while actuating must be significantly reduced. There are several ways to do this. One option is to redesign the shaft seal. The current U-Cup seal should be replaced by either a double o-ring configuration (which would require redesigning the seal cartridge), or possibly a BAL seal. Another option is to attach a steel bellows to the shaft. This would guarantee zero leakage, but will complicate the actuator motion and would be very expensive.

2. Better understanding of linkage assembly - A more precise model of the linkage assembly must be built and used for further motion control studies, including control systems software design. There are many complicated aspects to the motion of the linkages, which must be incorporated into the control process. The work already done on the two cam designs shows that small changes in the geometry of the assembly can drastically simplify the necessary motion of the actuator. This needs to be explored and quantified.

3. Exploration of alternatives to the air cylinder - Other methods for shroud removal should be investigated. Alternatives to the air cylinder, such as linear motors and stepping motors, would be simpler and preferable in many ways. Electronic motors are vacuum compatible, and unlike the air cylinder, can be more accurately position controlled.

Special Thanks to Daniel Stefanescu, Bud Fraze, Jerry Stewart and John Moody for their help and guidance. 


\section{Appendix}

\section{Vacuum Tests Log}

$8 / 16 / 02$

Purpose: Obtain chamber baseline to use as control data for cylinder tests.

Configuration: Refer to figure 1 . Note valve to cylinder lines is open to chamber vacuum.

Conclusions: Leak rate of chamber is $4.74 \mathrm{E}-3 \mathrm{~atm} \mathrm{cc} / \mathrm{min}$.

$8 / 16 / 02$

Purpose: Calculate cylinder leak rate at atmosphere and 80 psia using chamber baseline to normalize. Configuration: Refer to figure 2.

Conclusions: Normalized leak rate of cylinder at atm is $2.67 \mathrm{E}-2 \mathrm{~atm} \mathrm{cc} / \mathrm{min}$. Normalized leak rate of cylinder at $80 \mathrm{psia}$ is $4.04 \mathrm{~atm} \mathrm{cc} / \mathrm{min}$. This is a gross leak. Changes in front seal cartridge need to be applied as designed.

$8 / 19 / 02$

Purpose: Obtain new chamber baseline to confirm chamber integrity following modifications.

Configuration: Refer to figure 1a.

Conclusions: Leak rate of chamber is $7.39 \mathrm{E}-3 \mathrm{~atm} \mathrm{cc} / \mathrm{min}$, which is higher than before reconfiguration. Because we are checking gross leaks, this is satisfactory.

$8 / 19 / 02$

Purpose: Calculate cylinder leak rate with front seal cartridge.

Configuration: Refer to figure 2a.

Conclusions: Normalized leak rate of cylinder at atm is now $1.91 \mathrm{E}-3 \mathrm{~atm} \mathrm{cc} / \mathrm{min}$. Normalized leak rate of cylinder at $80 \mathrm{psia}$ is now $6.89 \mathrm{E}-3 \mathrm{~atm} \mathrm{cc} / \mathrm{min}$. These are significantly lower rates than those measured without front seal cartirdge, but are still orders of magnitude higher than published spec limit for NIF chamber (6E-5 atm cc/min). Interstitial space between shaft seal and o-ring end seal cartridge needs to be differentially pumped. Chamber baseline leak rate must also be decreased if possible, in order to sufficiently normalize lower (hopefully) cylinder leak rate.

$8 / 20 / 02$

Purpose: It was suggested that the covering of the BIMBA cylinder could be a source of leak. There is a weld interface on the rear of the cylinder that connects the body of the rear chamber to electrical components. We wanted to check this possibility.

Configuration: Refer to figure $2 \mathrm{c}$

Conclusion: There is no detectable leak on the body of the cylinder. There is also no leak through the Torr Seal ${ }^{\square}$ NPT connection (where pressurized air enters the cylinder).

$8 / 21 / 02$

Purpose: Obtain new chamber baseline and confirm that it is lower than baselines from $16^{\text {th }}$ and $19^{\text {th }}$. Configuration: Refer to figure $1 \mathrm{~b}$.

Conclusions: Leak rate of chamber is $5.32 \mathrm{E}-4 \mathrm{~atm} \mathrm{cc} / \mathrm{min}$. This should be sufficient for normalizing cylinder leak rates.

$8 / 22 / 02$

Purpose: Calculate cylinder leak rate with seals differentially pumped.

Configuration: Refer to figure $2 b$.

Conclusions: Normalized leak rate of cylinder at atm is now $1.84 \mathrm{E}-3 \mathrm{~atm} \mathrm{cc} / \mathrm{min}$. Normalized leak rate of cylinder at $80 \mathrm{psia}$ is now $4.65 \mathrm{E}-3 \mathrm{~atm} \mathrm{cc} / \mathrm{min}$. These rates are only a slight improvement on those without differential pumping of the seals. This implies that either the differential pumping is not working well due to the size of the interstitial pumping line, or some of the leak rate is due in large part to the lines going to the cylinder. Out-gassing was also suggested as a source of leak. Leak rate of lines needs to be quantified and accounted for in normalized cylinder leak rates. 
8/23/02

Purpose: Calculate leak rate of cylinder and lines together, and use as new baseline.

Configuration: Refer to figure 1c

Conclusions: Leak rate of chamber with lines pressurized to atm and evacuated cylinder is $8.23 \mathrm{E}-4 \mathrm{~atm}$ $\mathrm{cc} / \mathrm{min}$. Leak rate of chamber with lines pressurized to $80 \mathrm{psia}$ and evacuated cylinder is 1.99E-3 atm cc/min. This implies that much of the cylinder leak came from the lines and not out the shaft seal. Even despite this, we should be able to normalize the leak rate of the cylinder in the chamber with lines pressurized by subtracting this new baseline instead of our previous baseline.

$8 / 23 / 02$

Purpose: Calculate cylinder leak rate by normalizing with new baselines

Configuration: Refer to figure $2 b$

Conclusions: Normalized cylinder leak rates cannot be accurately calculated, because leaks in the lines dominate the overall leak rate. The normalizing thus produces leak rates for the cylinder that fall out of our pressure range detection. While we can produce numbers for the leak rate in this configuration, we are not confident with the accuracy of these calculations. As suggested in the Thursday meeting, we will reconfigure the same system with all metal lines.

$8 / 26 / 02$

Purpose: Obtain baseline of chamber with metal lines pressurized to atm and 80 psia. Then use these to calculate cylinder leak rate, taking into account leak in lines which we will not include as part of the cylinder leak.

Configuration: Same as $1 \mathrm{c}$, but with pressurized lines made of steel bellows instead of polyethylene.

Conclusions: Chamber baseline leak rate with atm in lines (steel) is $1.83 \mathrm{E}-4 \mathrm{~atm} \mathrm{cc} / \mathrm{min}$. Chamber baseline leak rate with 80 psia in lines (steel) is $1.03 \mathrm{E}-3 \mathrm{~atm} \mathrm{cc} / \mathrm{min}$. While this is a slight improvement on the poly lines, clearly the problem is not in the lines, but in the types of connections used inside the chamber. We need to change the lines to all-vcr connections. However, in the current chamber, this is not possible. Therefore, we need to design a new chamber in which we can install vcr connections. While we are designing a new chamber for this purpose, it also makes sense to simplify the chamber, using fewer ports and a smaller volume so that we might go to lower pressures. Nevertheless, we will continue the rest of the tests with steel lines to see what other issues arise, before building a new setup.

$8 / 26 / 02$

Purpose: Confirm that steel line setup is consistent with polyethylene by calculating normalized cylinder leak rates using same method.

Configuration: Same as $2 \mathrm{~b}$, but with steel lines.

Conclusions: After repeated measurements, we find cylinder leak rate (normalized) at 80 psia to be negative. In other words, the leak when the lines are connected to each other and the cylinder is open to vacuum is more than when the lines are connected to the cylinder. A possible reason for this that I came up with was that backflow from the interstitial space pump was leaking into the chamber when the cylinder was not connected to the lines, because of the higher pressure in the roughing pump. To confirm this theory I repeated the baseline test with configuration $1 \mathrm{~d}$. Again, the leak rate was lower with the cylinder connected. This might imply that out-gassing from the vacuum grease inside the cylinder, which is exposed to the chamber during baseline measurements, is causing the counter-intuitive results, in addition to line issues. When conducting baseline leak rate tests on the new chamber, we will do so without the cylinder in the system.

$8 / 29 / 02$

Purpose: Obtain leak rate for new chamber with lines capped and pressurized but no cylinder in chamber.

Configuration: Refer to figure le. All connections inside chamber are VCR. Test run with atm and 80 psia in lines, atm in interstitial pumpdown line. There is also a new method for pumping down the interstitial space. See documentation that follows for more on this.

Conclusions: Chamber baseline with lines capped and pressurized is $8.92 \mathrm{E}-5 \mathrm{~atm} \mathrm{cc} / \mathrm{min}$ for both tests (atm and $80 \mathrm{psia}$ in lines). This shows that lines are leak tight, and that chamber baseline pressure is suitable for measuring cylinder leak rate. In addition, the chamber is capable of reaching $1 \mathrm{E}-6$ baseline after extended pumping (baselines for tests were reached within 2 hours of beginning pump-down). It is now appropriate to proceed with cylinder leak rate tests. 
$8 / 30 / 02$

Purpose: Calculate cylinder leak rates at atm and 80 psia. Use baseline from previous test to normalize calculations.

Configuration: New chamber with setup same as in figure $2 \mathrm{~b}$.

Conclusions: Cylinder leak rate (normalized) is $2.14 \mathrm{E}-4 \mathrm{~atm} \mathrm{cc} / \mathrm{min}$. This leak rate is for a differentially pumped shaft seal. It is possible that the NPT connection between the lines and the cylinder is a source of leak, but as this is a part of the design for the BIMBA cylinder, it must be included in the overall leak rate. Torr Seal ${ }^{\square}$ epoxy was applied to this fitting to reduce the possibility of a leak, and no leak could be detected using a helium leak checker.

9/3/02

Purpose: Recalculate leak rates of cylinder and chamber after 4 days of pumping down the chamber, which has decreased substantially any out gassing in the system.

Configuration: Same as before.

Conclusions: Leak rates with the cylinder pressurized were lower than the chamber baseline leak rate of the previous week. Based on this result, I decided to not normalize my results for the cylinder leak rate, as it would have been impossible to calculate a chamber baseline that would correspond to my data. As it turned out, the leak rates increased so substantially when the cylinder was actuated that any normalizing would have been negligible. During these new tests, I also installed an ion gauge on the chamber to check my cold cathode gauge measurements from before. While I found a slight offset in the two, neither one was calibrated, so I did not find it necessary to recalculate my results from previous tests. The results of these final cylinder tests are:

- between 6E-05 and 9E-05 atm cc/min when not actuating

- between 4E-4 and 1E-3 while actuating

- $\quad$ higher after actuating (but still stationary) than before actuating

\section{Vacuum Test Configurations}

iigure 1a

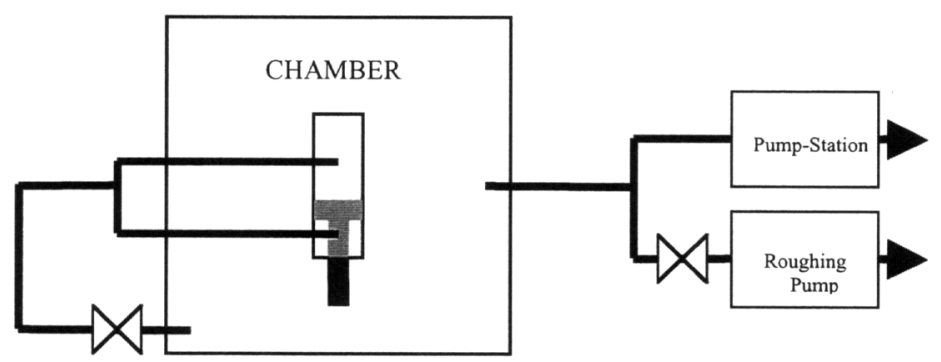

Figure 1b

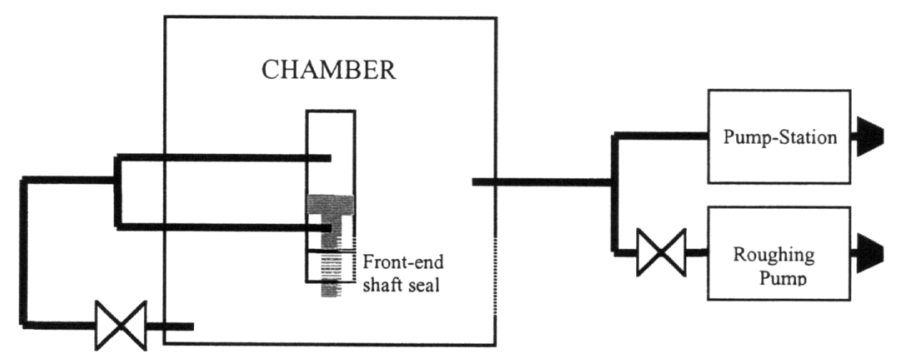

igure 1c

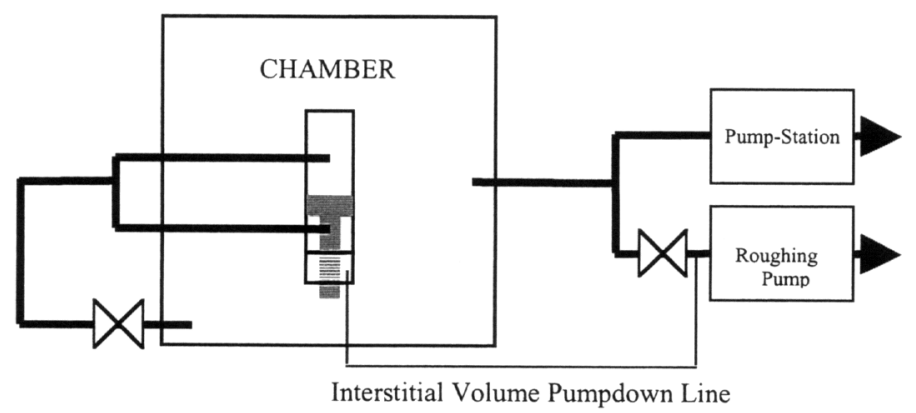

Figure 1d

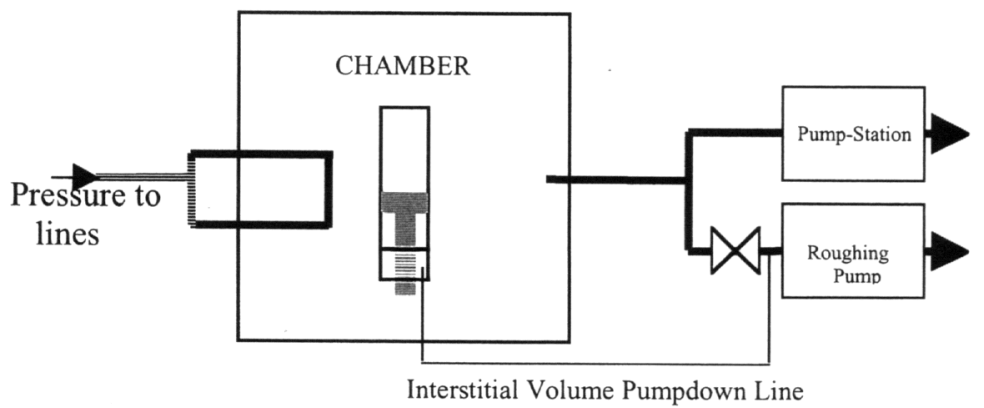


Figure 1e

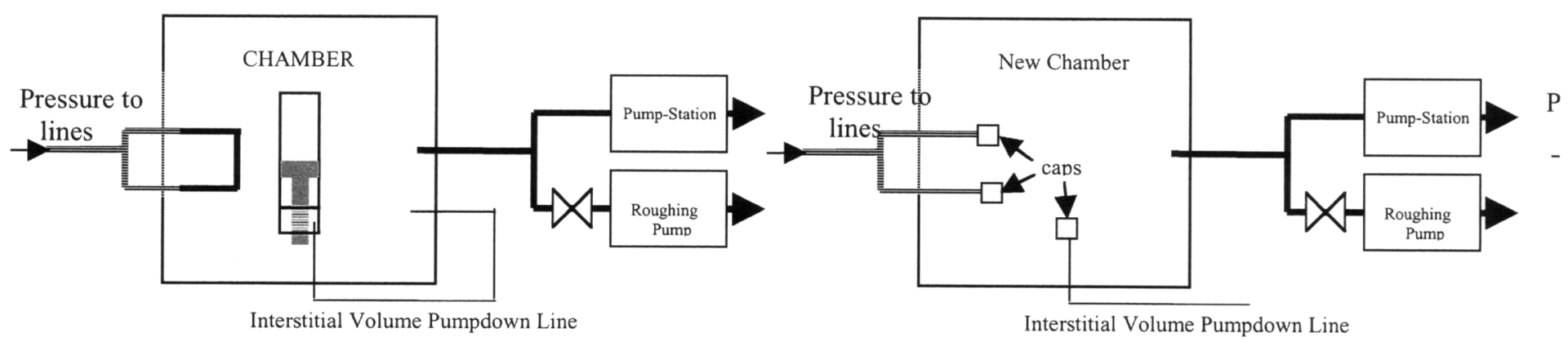

igure 2b

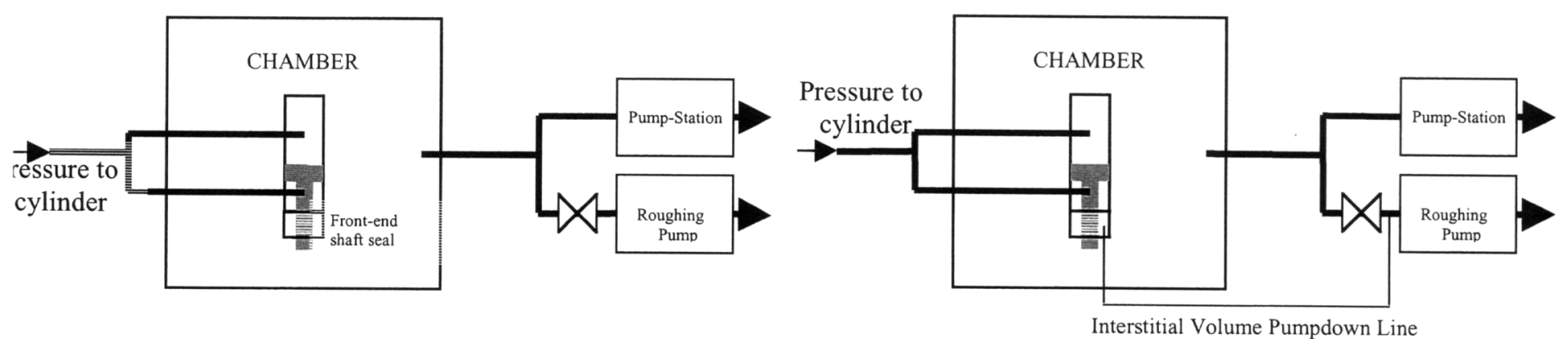


Figure 2d

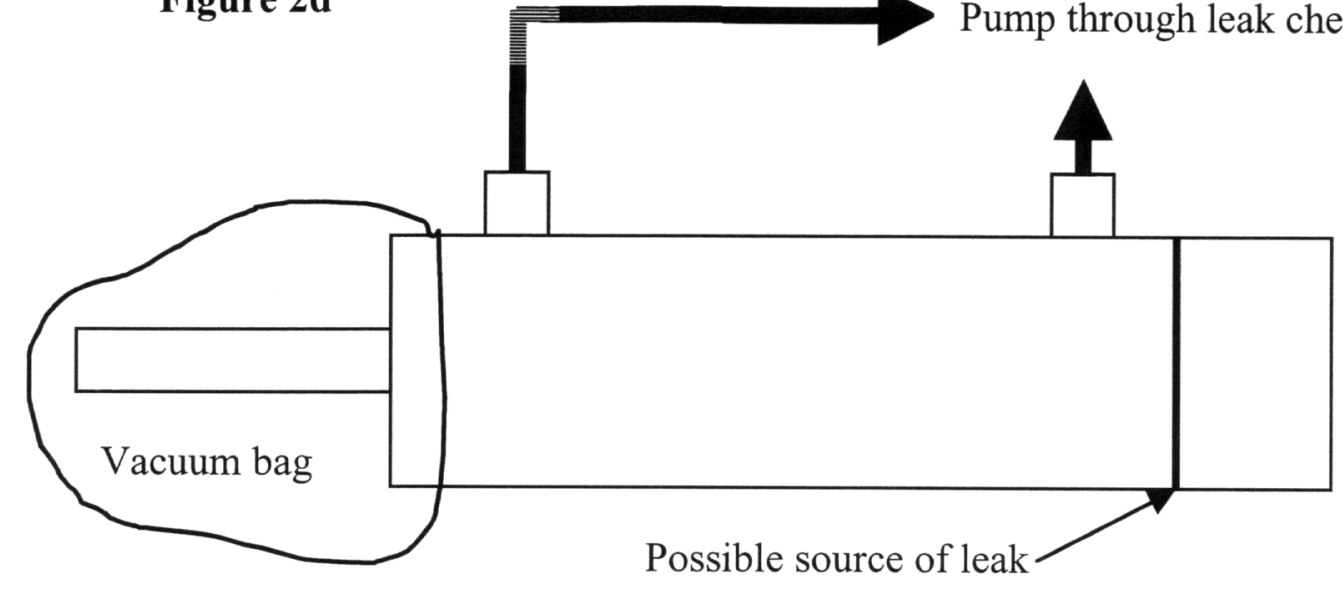

